THE aim of the present study is to determine whether patients with primary spontaneous pneumothorax (PSP) are subject to oxidative stress. For this purpose, we measured the activities of red blood cell superoxide dismutase, which is an antioxidant enzyme, and the level of plasma malondialdehyde, which is one of the lipid peroxidation markers, in a group of patients with PSP. The study was carried out with 16 patients with PSP and 24 healthy individuals. The two groups were similar to each other in terms of sex, age and smoking attitudes. Erythrocyte superoxide dismutase activity was found to be significantly lower in patients with PSP than in the control group $(p<$ 0.01 ). The plasma malondialdehyde levels were significantly high in patients with PSP $(p<0.01)$. Our results suggest that oxidative stress may contribute to the pathogenesis of PSP.

Key words: Superoxide dismutase, Malondialdehyde, Primary spontaneous pneumothorax

\section{Levels of superoxide dismutase and malondialdehyde in primary spontaneous pneumothorax}

\author{
Erhan Tabakoglu ${ }^{1, C A}$, Senturk Ciftci ${ }^{2}$, \\ Osman Nuri Hatipoglu ${ }^{1}$, Gündeniz Altıay ${ }^{1}$ and \\ Tuncay Caglar ${ }^{1}$
}

${ }^{1}$ Department of Chest Medicine, and ${ }^{2}$ Department of Biochemistry, Trakya University Medical Faculty, 22030 Edirne, Turkey

${ }^{\mathrm{CA}}$ Corresponding Author
Tel: +902842357641
Fax: +902842352730
E-mail: erhantabakoglu@trakya.edu.tr

\section{Introduction}

In normal circumstances all aerobic cells form reactive oxygen radicals, during respiration phagocytes, arachidonic acid metabolism, and other ordinary processes while metabolising oxygen. These radicals are quickly detoxified by antioxidant systems in a normal organism. However, if the formation of free radicals comes to a rate that exceeds the capacity of the antioxidant systems in the cells, the free radicals formed may damage basic molecules (lipids, proteins, carbohydrates and nucleic acids). ${ }^{1}$

Antioxidant enzymes, one of which is superoxide dismutase (SOD), bear a vital significance for protection against oxidative stress. ${ }^{2}$ Lipid peroxidation is described as a chemical phenomenon that is initiated by free radicals and that involves the oxidation of fat cells. ${ }^{3}$ After lipid peroxidation, lipid hydroproxydes are transformed into aldehyde and other carbonyl composites. Measuring the quantity of plasma malondialdehyde (MDA), which is one of these composites, is a method frequently used in determining lipid peroxidate levels. In this way, the MDA plasma concentration and the degree of stress reactions can be predicted. The physical harm in cell membranes caused by lipid peroxidation is irreversible and may eventually lead to cell death.

In lung pathology, conditions such as emphysema, bronchopulmonary dysplasia, pneumoconiosis, bleo-

Note: This study was presented as a thematic poster in ERS 2002 annual congress, Stockholm, Sweden. mycin toxicity, paraquat toxicity, butylhydroxytoluene toxicity, mineral dust toxicity, respiratory distress syndrome, asthma and cigarette smoke toxicity have been related to oxygen radicals. ${ }^{4}$ However, to the best of our knowledge, there is no other similar study in the literature about the role of oxidative stress in primary spontaneous pneumothorax (PSP). For that reason, we wanted to investigate whether there is any relation between the increase in oxidative stress and PSP.

\section{Materials and methods}

Sixteen patients ( 14 males and two females), $38 \pm 11$ years old on average, who had PSP in the past were invited to our polyclinic. Their smoking and pneumothorax histories were recorded. Ten of these patients were smokers. Their serum SOD and MDA levels were measured. A control group was formed with 24 healthy individuals similar to each other in terms of smoking habits, gender, and age $(p>0.05)$. Sixteen of these individuals were smokers. Fourteen of them were male and their average age was $45 \pm 11$ years. The erythrocyte SOD activities were analysed with a Randox Cat No:SD 125 kit and were evaluated with a Shimadzu Spectro Photometer machine. The plasma MDA levels were measured in accordance with the method developed by Hiroshi et al. ${ }^{5}$

The overall analysis was carried out with the SPSS statistical software (licensed to Trakya University). The Mann-Whitney test was used for analysis of 
non-parametric data. Statistic significance was defined as $p<0.05$.

\section{Results}

The average level of SOD in patients with PSP was $730.5 \pm 97$ while that level was $1385 \pm 315$ in the control group $(p<0.01)$. The average level of MDA in patients with PSP was $5.5 \pm 2.2$ whereas this was $2.9 \pm 1$ in the control group $(p<0.01)$. These results are presented in Table 1.

\section{Discussion}

Recent studies show that oxidative stress takes part in the aetiopathogenesis of many illnesses. Here, two types of damage may come to play. First, the free oxygen radicals may increase. Second, one of the defence mechanisms of the body may be malfunctioning due to the lack of SOD.

The PSP appears in males with a ratio of 7.4/ 100,000 per year and in females with a ratio of 1.2/ 100,000 per year. A family tendency has been reported. The HLA haplotype A2, B40, $\alpha 1$ antitrypsine phenotype M1M2 has been detected as a risk factor. ${ }^{6}$ It appears frequently with patients with connective tissue disorders, such as Marfan syndrome. It concerns smoking habits. Subplevral bullae and blebs are crucial factors in this illness. However, the causes of subplevral bullae and blebs are unknown. The fact that there is a co-relation between smoking and PSP suggests that there is a connection between the illness and oxidative stress.

Table 1. SOD and MDA levels in the control group and in patients with PSP

\begin{tabular}{lcc}
\hline & $\begin{array}{c}\text { SOD } \\
(\mathrm{U} / \mathrm{g} \mathrm{Hb} \pm \mathrm{SD})\end{array}$ & $\begin{array}{c}\text { MDA } \\
(\mathrm{nmol} / \mathrm{ml} \pm \mathrm{SD})\end{array}$ \\
\hline Patients with PSP & $730.5 \pm 97$ & $5.5 \pm 2.2$ \\
Control group & $1385 \pm 315$ & $2.9 \pm 1$ \\
$p$ value & $<0.01$ & $<0.01$ \\
\hline
\end{tabular}

$\mathrm{Hb}$, haemoglobin; SD, standard deviation.
The lungs are constantly exposed to oxidants present in the air inhaled, such as cigarette smoke and ozone, or those released from airspace inflammatory leukocytes. These oxidants cause direct damage to the lung interstitium. Airspace epithelial injury, which is encountered in asymptomatic smokers, may result in enhanced epithelial permeability. Oxidative stress results in centrilobular emphysema. ${ }^{7}$

These observations suggest to us that oxidative stress may lead to the illness by triggering the formation of subplevral bullaes brought about by exposure to oxidative stress. The existence of this destructive effect in apexes with the highest pulmonary ventilation may mean that there is no good defence mechanism against external destructive agents like smoke and ozone. The lung is protected against oxidative stress by various antioxidants, including the SOD system. Due to a decrease in SOD, which is part of the defence mechanism against oxidative stress, lipid peroxidation increases. The latter is a sign of destruction in cells. This damage may result in bullae and blebs, which are well-known elements triggering the PSP.

In conclusion, oxidative stress plays a major role in the aetiopathogenesis of the PSP illness.

ACKNOWLEDGEMENTS. The authors thank Sedat Ustundag and Ufuk Berberoglu for their assistance in the preparation of this study.

\section{References}

1. Sies H. Oxidative stress: from basic research to clinical application. Am J Med 1991; 91(3C): 315-385.

2. Loeper J, Goy J, Rozenstain L, Bedu O, Moisson P. Lipid peroxidation and protective enzymes during myocardial infarction. Clin Chim Acta 1991; 196: $119-126$

3. Halliwell B. Oxidative stress. Nutrition and health. Experimental strategies for optimisation of nutritional antioxidant intake in humans. Free Radic Res 1996; 25: 57-74

4. Bast A, Haenen GRM, Doelman CJA. Oxidants and antioxidants: state of the art. Am J Med 1991; 91: 2-13.

5. Hiroshi O, Habuko D, Yagi K. Assay for lipid peroxidation in animal tissues by thiobarbitüri acid reaction. Anal Biochem 1979; 95: 351-358.

6. Sharpe IK, Ahmad M, Braun W. Familial spontaneous pneumothorax and HLA antigens. Chest 1980; 78: 264-268.

7. Janoff A. Elastases and emphysema: current assessment of the proteaseantiprotease hypothesis. Am Rev Respir Dis 1985; 132: 417-433.

\section{Received 8 April 2004 \\ Accepted 22 April 2004}




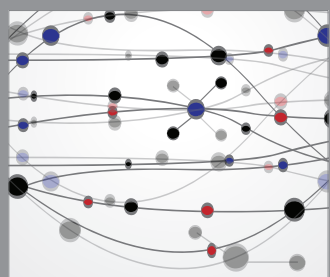

The Scientific World Journal
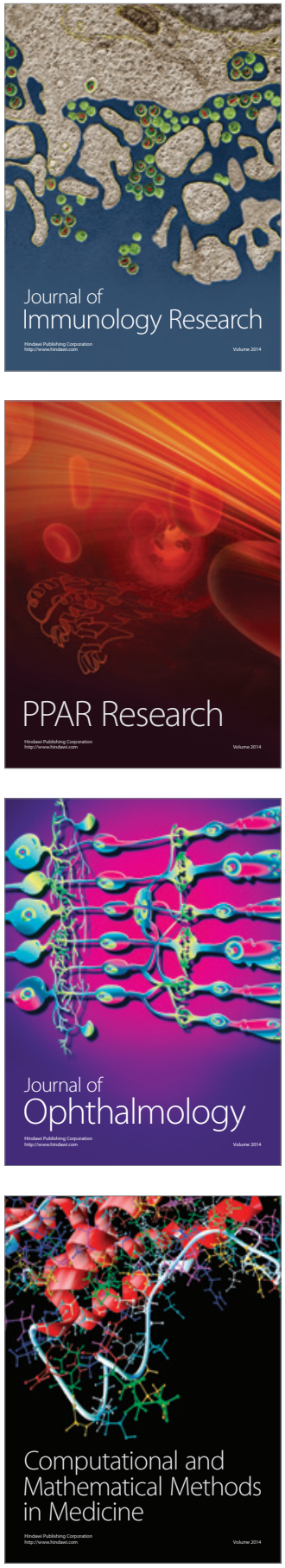

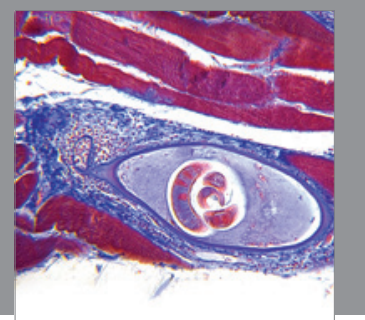

Gastroenterology

Research and Practice
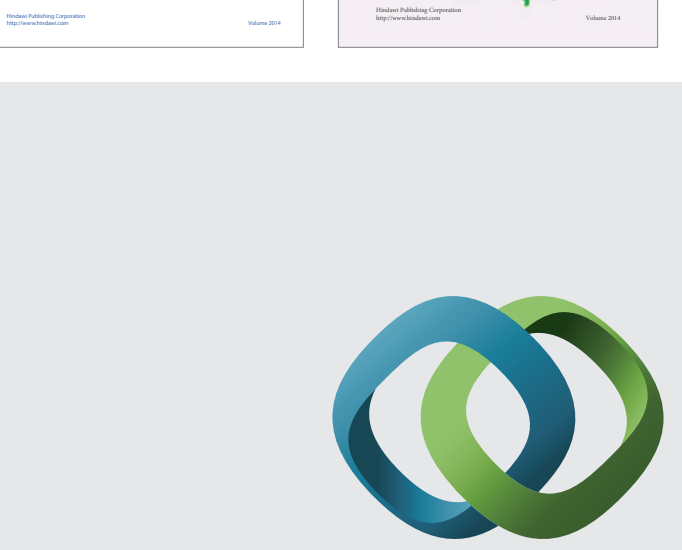

\section{Hindawi}

Submit your manuscripts at

http://www.hindawi.com
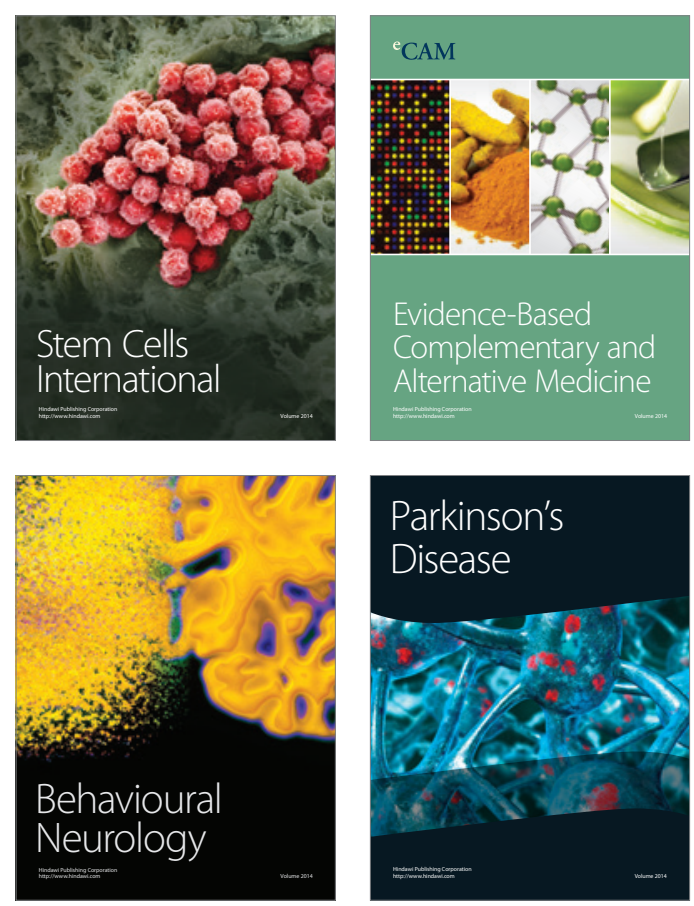

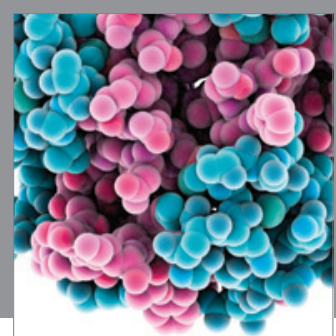

Journal of
Diabetes Research

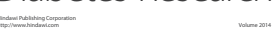

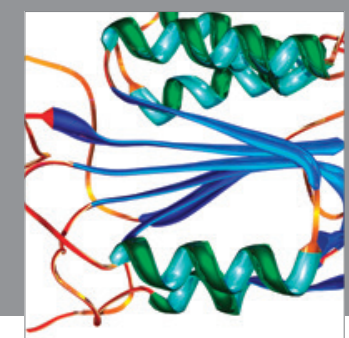

Disease Markers
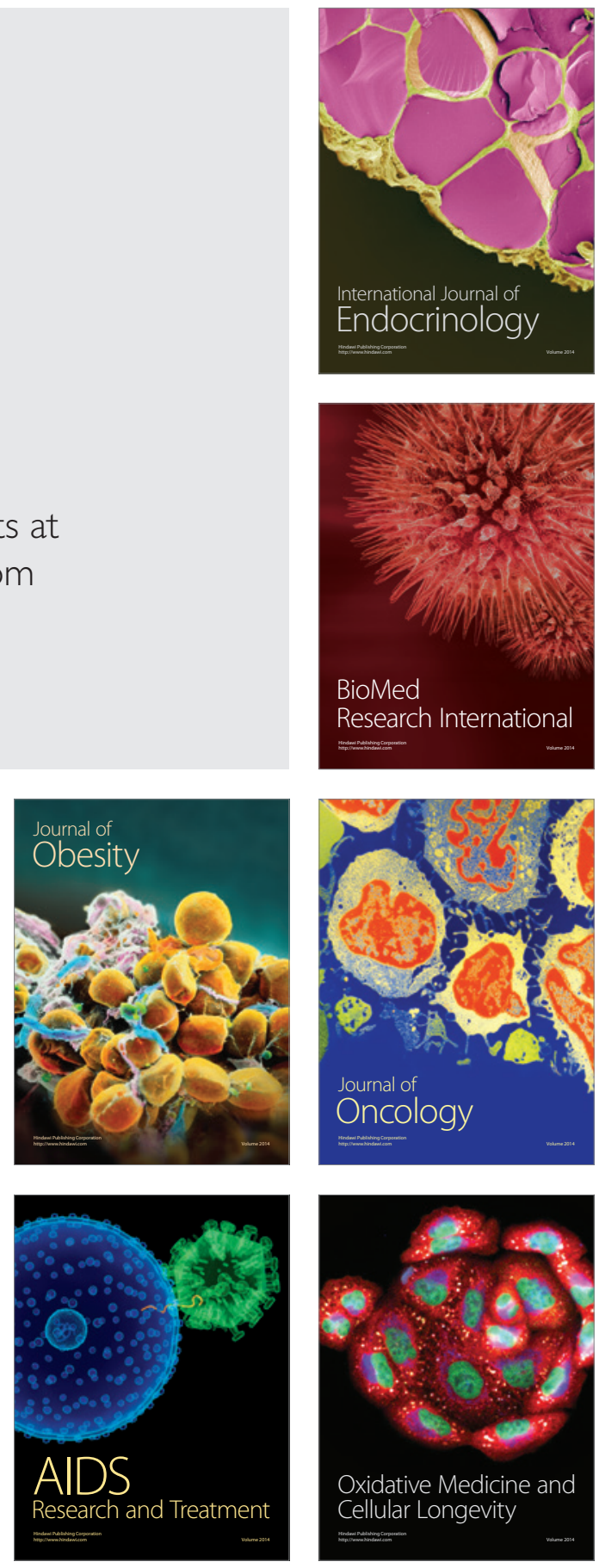